\begin{tabular}{|l|l|l||}
\hline \multicolumn{2}{|c|}{ PublisherInfo } \\
\hline \hline PublisherName & $:$ & BioMed Central \\
\hline \hline PublisherLocation & $:$ & London \\
\hline \hline PublisherImprintName & $:$ & BioMed Central \\
\hline \hline
\end{tabular}

\title{
A phase II trial of a histamine antagonist (DPPE) and doxorubicin in metastatic breast cancer
}

\begin{tabular}{||l|l|l||}
\hline \multicolumn{2}{|c||}{ ArticleInfo } \\
\hline \hline ArticleID & $:$ & 3662 \\
\hline \hline ArticleDOI & $:$ & $10.1186 /$ bcr-1999-66640 \\
\hline \hline ArticleCitationID & $:$ & 66640 \\
\hline \hline ArticleSequenceNumber & $:$ & 28 \\
\hline \hline ArticleCategory & $:$ & Paper Report \\
\hline ArticleFirstPage & $:$ & 1 \\
\hline \hline ArticleLastPage & $:$ & 4 \\
\hline \hline & $:$ & RegistrationDate : 1999-11-15 \\
ArticleHistory & $:$ & OnlineDate \\
\hline \hline ArticleCopyright & $:$ & Current Science Ltd1999-11-15 \\
\hline \hline ArticleGrants & $:$ & \\
\hline \hline ArticleContext & $:$ & 1305822 \\
\hline \hline
\end{tabular}




\section{Keywords}

Doxorubicin, histamine antagonist (DPPE), metastatic breast cancer, phase II

\section{Introduction}

N,N-diethyl-2-[4-(phenylmethyl)phenoxy]ethanamine.HCl (DPPE) is a diphenylmethane-derivative arylalkylamine, similar in structure to various $\mathrm{H1}$-antihistamines and tamoxifen, that has the ability to antagonize histamine binding in microsomes and nuclei. Preclinical studies of DPPE indicate a wide variety of biological effects, including inhibition of concanavalin A?induced mitogenesis in normal mouse spleen cells and protection of rodent bone marrow from toxic doses of doxorubicin and fluorouracil. DPPE also has been observed to potentiate the cytotoxicity of several classes of chemotherapeutic agents, including doxorubicin. In vitro, DPPE potentiation of the cytotoxicity of doxorubicin, paclitaxel, and vinblastine in human colon cancer cells, has been linked to it acting as a substrate for the P-glycoprotein (P-gp) pump while in mice, when combined with anthracyclines, DPPE increased the cure rate of experimental tumours. In early phase I and II clinical trials DPPE, combined with single agents (including doxorubicin), showed evidence of activity in heavily pre-treated patients. A previous 23 patient study of DPPE with doxorubicin in anthracycline-naive women with metastatic breast cancer reported overall and complete responses rates of $69 \%$ and $30 \%$, respectively, with an acceptable level of toxicity. On the basis of these findings, the National Cancer Institute of Canada Clinical Trials Group conducted a multicenter phase II trial of the DPPE/doxorubicin combination in anthracycline-naive women with metastatic breast cancer.

\section{Aims}

To evaluate the efficacy and toxicity of the novel intracellular histamine antagonist DPPE in combination with doxorubicin, in women with anthracycline-naive metastatic breast cancer.

\section{Comments}

This is an interesting study examining the impact of the addition of a novel non-cytotoxic agent (N,Ndiethyl-2-[4-(phenylmethyl)phenoxy]ethanamine.HCl) in patients with metastatic breast cancer. The 
antitumour effects of DPPE/doxorubicin resulting in a 52.5\% response rate seems encouraging. How DPPE might increase the therapeutic index of doxorubicin remains unclear. One hypothesis is that DPPE may increase tumour response by altering doxorubicin pharmacokinetics. However, the fact that haematologic toxicity with DPPE/doxorubicin did not seem to be more severe than that seen with singleagent doxorubicin indicates that a significant pharmacokinetic interaction is unlikely and that other cellular mechanisms may be important (eg acting as a substrate for the P-glycoprotein [P-gp] pump). Whilst the results of this study are intriguing, the results of randomised phase III trial will be needed before definitive conclusions about the effect of DPPE on the therapeutic index of doxorubicin can be made.

\section{Methods}

Forty-two women were treated. The age range was 32 to 77 years old (median 59 years). Patients had to be anthracycline-naive, but were allowed to have previously had one nonanthracycline regimen. Following premedication with an antiemetic and sedating regimen, the DPPE $(6 \mathrm{mg} / \mathrm{kg}) \mathrm{was}$

administered intraveneously over $80 \mathrm{~min}$ and doxorubicin $\left(60 \mathrm{mg} / \mathrm{m}^{2}\right)$ was given over the last $20 \mathrm{~min}$ of the DPPE infusion. Treatment was given every 21 days for a maximum of 7 cycles.

\section{Results}

All 42 patients were assessable and 35 patients received at least 4 courses of treatment. Only 4 of 209 cycles required doxorubicin dose reduction, with no dose reductions of DPPE. Approximately $75 \%$ of the patients were administered DPPE and doxorubicin at $90 \%$ of planned dose intensity. The overall response rate was $52.5 \%$, with $4(9.5 \%)$ patients achieving a complete response and $18(43 \%)$ a partial response. Responses were seen in all sites of disease. Four patients $(9.5 \%)$ had progressive disease during treatment. The median time to progression was 6.4 months, and the median response duration was 4.7 months (range, 4.1 to 5.1 months) for complete responders, and 7.7 months (range, 2.1 to 13.6 months) for partial responders. Toxicities associated with the combination were similar to those seen with doxorubicin administered alone. Of the patients, $62 \%$ experienced grade 4 neutropenia, and eight required hospital admission for treatment-related complications (five having either febrile neutropenia or severe infection, and three patients with hallucinations, vomiting, and dyspnea). Six patients came off the study because of toxicity or possible toxicity. There were no treatment-related deaths. There were toxicities peculiar to the DPPE, in particular CNS toxicity, consisting of mild hallucinations, cerebellar effects (dizziness and ataxia), and motion sickness. These generally occurred during the infusion and persisted for a few hours afterward. In some patients, nausea and emesis continued for several days after treatment and seemed more prolonged than usually seen with doxorubicin alone. Cardiac toxicity, defined as a $20 \%$ decrease in LVEF from baseline, or a drop in LVEF to less than $50 \%$, was seen in eight patients (19\%): only three had clinical symptoms of congestive heart failure (developing after five, six, and seven cycles of therapy). 


\section{Discussion}

In women with anthracycline-naive advanced breast cancer, the combination of DPPE and doxorubicin produced an overall response rate of $52.5 \%$, with a complete response rate of $9.5 \%$. This compares favourably to a $31 \%$ overall response rate (3\% complete responses) seen in a similar group of women (although less heavily pre-treated) treated with the same dose/schedule of single-agent doxorubicin in a recently reported randomised study with identical eligibility criteria. Most of the toxicities noted were those expected secondary to doxorubicin, although the CNS toxicities observed at the time of treatment were attributable to the DPPE. The main troublesome toxicity appeared to be prolonged nausea and vomiting. Although the incidence (19\%) of cardiac toxicity was high, only three patients developed clinical congestive heart failure. The results of this study are of great enough significance to encourage further investigation. A prospectively randomised international study has been initiated comparing doxorubicin $60 \mathrm{mg} / \mathrm{m}^{2}$ with DPPE $6 \mathrm{mg} / \mathrm{kg}$ plus doxorubicin $60 \mathrm{mg} / \mathrm{m}^{2}$ in patients with metastatic breast cancer

\section{References}

1. Khoo K, Brandes L, Reyno L, Arnold A, Dent S, Vandenberg T, Lebwohl D, Fisher B, Eisenhauer E: Phase II trial of N,N-Diethyl-2-[4-(phenylmethyl)phenoxy]ethanamine. $\mathrm{HCl}$ and doxorubicin chemotherapy in metastatic breast cancer: a National Cancer Institute of Canada clinical trials group study. J Clin Oncol. 1999, 17: 3431-3437. 